\title{
A IDEOLOGIA E O PODER DISCIPLINAR COMO FORMAS DE DOMINAÇÃO
}

\author{
Liliana Bueno dos Reis GARCIA*
}

RESUMO: Este artigo objetiva uma reflexão sobre o conceito marxista de ideologia, ao mesmo tempo em que busca entender a transposição do n'vel da consciéncia para o nlvel da corporalidade física, feita por Michel Foucault, como forma de instituição do poder disciplinar sobre os indivlduos, como meio de dominação muito mais eficaz do que a própria consciéncia.

UNITERMOS: Ideologia; alienação; dialética; consciência; falsa consciência; poder; micropoderes; poder disciplinar.

O termo ideologia surge pela primeira vez no século XIX (1801), com Destutt de Tracy, no livro intitulado Eléments d’ldéologie. Este busca, numa primeira tentativa, a elaboração da ciência da gênese das idéias.

Porém, somente com Marx, em A Ideologia Alemã, a concepção de ideologia ganha nova conotação. Marx constrói uma ciência da história e toma a ideologia como objeto dessa ciência.

Marx aceita como pressuposto básico de toda a história humana, a existência de seres humanos vivos, reais, produzindo as suas próprias condições reais de sobrevivência.

"A forma como os homens produzem esses meios depende em primeiro lugar da natureza, isto é, dos meios de existência, já elaborados e que lhes é necessário reproduzir; mas não devemos considerar esse modo de produção deste único ponto de vista, isto é, enquanto mera reprodução da existência física dos indivíduos. Pelo contrário, já constitui um modo determinado de atividade de tais indivíduos, uma forma determinada de manifestar a sua vida, um modo de vida determinado. A forma como os indivíduos manifestam a sua vida reflete muito exatamente aquilo que são. $O$ que não coincide, portanto, com a sua produção, isto é, tanto com aquilo que produzem como com a forma como produzem. Aquilo que os indivíduos são depende, portanto, das condições materiais da sua produção" (5, p. 19).

Segundo o marxismo, nada existe além da natureza e dos homens. Contudo, nenhum desses elementos pode ser tomado, separadamente, para explicar o desenvolvimento das sociedades. Somente sua unidade dialética pode fornecer a resposta adequada, e sua unidade dialética é o trabalho e a produção. Sem o trabalho, sem a produção, a sociedade não pode nem viver nem se desenvolver: o trabalho é a condição objetiva da existência humana.

Portanto, para viver, os homens precisam de bens materiais e é necessário que a sociedade os produza. Para produzi-los é preciso instrumentos apropriados. É preciso saber fabricá-

\footnotetext{
* Departamento de Planejamento Regional - Instituto de Geociências e Ciências Exatas - UNESP - 13500 - Rio Claro - SP.
} 
los e saber usá-los. Porém, o desenvolvimento das forças produtivas está condicionado pelo desenvolvimento dos instrumentos de produção que vão se aperfeiçoando no decorrer da história da humanidade. Esse desenvolvimento constitui a base da divisão do trabalho.

Temos primeiro, a divisão de trabalho entre pescadores e caçadores primitivos, entre as tribos que criam animais e depois se dedicam à agricultura. Temos, posteriormente, a divisão entre os ofícios e a agricultura. Esta, por sua vez, determina a troca de produtos entre agricultores e artesão, e determina a busca de uma forma de distribuição distinta da repartição doméstica. Foi assim que apareceu, em condições determinadas, a mercadoria. É também nessa divisão de trabalho que se encontra embutida a diferenciação progressiva entre campo e cidade. A cidade, tornando-se o centro da produção artesanal e da troca.

Deste modo, o desenvolvimento e o aperfeiçoamento dos instrumentos de produção foram realizados pelos homens que, por sua vez, estão relacionados com a produção e não independentes deles. Conseqüentemente, ao mesmo tempo que os instrumentos de produção mudam e se desenvolvem, os homens, elementos essenciais das forças produtivas, concomitantemente mudam e se desenvolvem. Sua experiência de produção, seus hábitos de trabalho, sua aptidão em manejar os instrumentos de produção transformam-se e se aperfeiçoam (3).

A ferramenta é o intermediário entre o homem e a natureza. Esta tem 'como função a transformação dos objetos naturais em objetos utilizáveis pelo homem. A ferramenta vem, portanto, exprimir de um modo profundamente dialético a luta do homem contra a natureza e as forças produtivas exprimem o comportamento dos homens em relação aos objetos e às forças da natureza de que os homens se servem para produzir os bens materiais necessários à sobrevivência (3).

Embora a produção seja a luta do homem contra a natureza, em parte alguma essa luta é isolada. A produção é um ato social, portanto, uma produção social que gera relações sociais.

Porém, o que determina. o caráter das relações de produção é a propriedade dos meios de produção. Daí a afirmação de que o indivíduo desprovido desses meios só pode viver sob a condição de aceitar a dominação de quem os possui. Portanto, a propriedade ou não dos meios de produção gera a existência de dominantes e dominados.

"A matéria do materialismo histórico-dialético são os homens produzindo, em condições determinadas, seu modo de se reproduzirem como homens e de organizarem suas vidas como homens. Assim sendo, a reflexão não é impossivel. Basta que percebamos que o sujeito da história, seu agente, embora não seja o Estado, é sujeito: são as classes sociais em luta. Essas não são coisas nem idéias, mas são relações sociais determinadas pelo modo como os homens, na produção de suas condições materiais de existência, se dividem no trabalho, instauram formas determinadas da propriedade, reproduzem e legitimam aquela devisão e aquelas formas por meio das instituições sociais e políticas, representam para si mesmo o significado dessas instituições através de sistemas determinados de idéias que exprimem e escondem o significado real de suas relações. As classes sociais são o fazer-se classe dos indivíduos em suas atividades econômicas, políticas e culturais" (1, p. 53).

Essas relações de produção levam à alienação do processo de trabalho. O próprio trabalho transforma-se numa mercadoria, gerando o que Marx denomina de fetiche da mercadoria, onde as coisas parecem adquirir uma alma própria, dando-se a personificação das coisas e a materialização das pessoas.

A propriedade privada dos meios de produção e a divisão social do trabalho não são, segundo Marx, o suficiente para mostrar a desigualdade entre pessoas. Essa desigualdade é 
mostrada através das mercadorias. A própria produção da mercadoria é fetichizada. Dá-se a coisificação, isto é, uma coisa existe em si e por si. Para Marx, a mercadoria é o substrato intelectual do sistema capitalista.

"Com efeito, o trabalhador passa a ser uma coisa denominada força de trabalho que recebe uma outra coisa chamada salário. O produto trabalho passa a ser uma coisa chamada mercadoria, que possui uma outra coisa, isto é, um preço. O proprietário das condições de trabalho e dos produtos do trabalho passa a ser uma coisa chamada capital, que possui uma outra coisa, a capacidade de ter lucros. Desaparecem os seres humanos, ou melhor, eles existem sob a forma de coisas" (1, p. 58).

Desta forma, para Marx, a produção das idéias, de representações e da consciência está diretamente ligada à atividade material dos homens. "São os homens que produzem as suas representações, as suas idéias, mas os homens reais, atuantes e tais como foram condicionados por um determinado desenvolvimento das suas forças produtivas e do modo de relações que the corresponde" (5, p. 25).

As representações ideológicas partem do homem e de suas atividades reais. Portánto, "não é a consciência que determina a vida, mas sim a vida que determina a consciência" (5, p. 26).

Com Marx, a ideologia passa a ser o sistema das idéias, das representações que domina o espírito de um homem ou um grupo social. E isto só é possível quando se completa a divisão social do trabalho material e espiritual.

Desta forma, as ideologias são representações ordenadas de idéias, porém, se acham separadas e independentes das condições materiais de vida, pois, seus produtores, os ideólogos, não se encontram vinculados à produção material das condições de existência. "As idéias não aparecem como produtos do pensamento de homens determinados, mas como entidades autônomas descobertas por tais homens" (1, p. 66).

As contradições explicitadas pelas idéias são resultantes do fato de que o mundo social é contraditório. Isto leva à constatação da desigualdade social onde uns pensam, uns trabalham, outros produzem e outros consomem.

Esta contradição leva ao dualismo que existe na relação entre alienação e ideologia. "A ideologia não é um processo subjetivo consciente, mas um fenômeno objetivo e subjetivo involuntário produzido pelas condições da existência social dos indivíduos" (1, p. 78).

A ideologia produz idéias que vêm confirmar a alienação. Através da ideologia dominante na sociedade capitalista, os homens são vistos como desiguais por natureza, mas que ao mesmo tempo é dado a eles o direito do trabalho. Também, ao mesmo tempo em que reforça sua desigualdade, reforça a igualdade dos mesmos perante o Estado, camuflando o papel do Estado como um agente de coerção ou um instrumento de dominação.

Para o materialismo histórico e dialético, "é impossivel compreender a origem e função da ideologia sem compreender a luta de classes, pois a ideologia é um dos instrumentos da dominação de classe e uma das formas da luta de classes. A ideologia é um dos meios usados pelos dominantes para exercer a dominação, fazendo com que esta não seja percebida como tal pelos dominados... o que torna a ideologia possivel é a separação entre trabalho material e intelectual... é também o fenômeno da alienação e a luta de classes, ou seja, a dominação de uma classe sobre as outras... Podemos acrescentar que o poder ou a eficácia da ideologia aumentam quanto maior for a sua capacidade para ocultar a origem da divisão social em classes e a luta de classes" (1, p. 87-90). 
A ideologia para Marx age como um instrumento de dominação de uma classe sobre a outra. Ela é resultante da prática social dos homens, representa as idéias dominantes de uma dada sociedade e de uma determinada época. Ela se generaliza, tomando as idéias da classe dominante como as idéias de todas as classes que compõem a sociedade. Portanto, gera a afirmação de que a classe dominante é a classe que detém o poder material. A ideologia é, portanto, segundo Marx, um instrumento de dominação. Coloca em questão o problema da consciência necessariamente falsa, que a própria prática do capitalismo exige, isto é, contrapõe a ideologia à realidade fetichizada. Há um vínculo da consciência às aparências da formação econômica. Não se chega à essência das coisas. O fenômeno do capitalismo é tratado tal como aparece. Ele próprio necessita dessa falsa consciência para sobreviver.

Saindo de Marx, o problema da ideologia gera um impasse teórico. Em função disto, dada a complexidade suscitada pelo problema, passaremos à análise do pensamento de Michel Foucault a fim de buscar a compreensão da forma como a questão do poder e da dominação na sociedade capitalista são colocadas pelo autor em questão.

Em Foucault, a questão da alienação sai fora das relações materiais e das relações de propriedade, entre classe burguesa e proletariado. As pessoas são colocadas em outro nivel e a ideologia passa a ser vista não como representações, mas como formas específicas de poder, que, ao seu ver, são diluídas em micropoderes no cotidiano.

Para Foucault "a noção de ideologia parece dificilmente utilizável por três razões. A primeira é que, queira-se ou não, ela está sempre em oposição virtual a alguma coisa que seria a verdade. Ora, creio que o problema não é de se fazer a partilha entre o que um discurso revela da cientificidade e da verdade e o que revelaria de outra coisa; mas de ver historicamente como se produzem efeitos de verdade no interior de discursos que não são em si nem verdadeiros nem falsos. Segundo inconveniente: refere-se necessariamente a alguma coisa como o sujeito. Enfim, a ideologia está em posição secundária com relação a alguma coisa que deve funcionar para ela como infra-estrutura ou determinação econômica, material, etc. Por estas três razões creio que é uma noção que não deve ser utilizada sem precauções" (2, p. 7).

Foucault procura, portanto, libertar-se da noção de ideologia tal como Marx a coloca, isto é, ao nivel do consciente, ou seja, gerando e produzindo a falsa consciência.

Diante da complexidade do conceito de ideologia, Foucault propõe estudar o corpo e o objeto ao invés de estudar a constituição do sujeitọ. Ele passa, portanto, para a análise da constituição do objeto, tornando a questão do corpo, como questão central em detrimento à questão da consciência. Para ele, o que interessa é a exterioridade, isto é, algo que pode ser observado como dado real, objetivo e concreto.

Portanto, tudo vai se resumir em torno do corpo e do espaço formado ao seu redor. Antes da consciência existe o domínio do corpo. Assim afirmando, está saindo do domínio da consciência propagado por Marx. O exercício do poder sobre o corpo é muito mais eficiente como forma de controle do que o exercício da consciência. Esta é a questão central discutida por Foucault.

O sujeito é visto como uma questão menos teórica e mais prática, sujeitado à tecnologia do poder. Esta sujeição passa a ser o centro de toda e qualquer sociedade, segundo Foucault.

Ao dar ênfase ao poder, torna-se necessário entendermos a maneira pela qual o poder é constituído, segundo Foucault.

"Não existe em Foucault uma teoria geral do poder. O que significa dizer que suas análises não consideram o poder como uma realidade que possua uma natureza, uma essência que ele procuraria definir por suas características universais. Não existe algo unitário e global chamado

Trans/Form/Ação, São Paulo, 11: 53-59, 1988. 
poder, mas unicamente formas díspares, heterogêneas, em constante transformação. O poder não é um objeto natural, uma coisa, é uma prática social e, como tal, constituída historicamente" (4, p. X)

Para Foucault o poder não se constitui somente ao nível do Estado, mas também ao nível das instituições. O poder assume formas difusas, pois "o que aparece como evidente é a existência de formas de exercício do poder diferentes do Estado, a ele articuladas, de maneiras variadas e que são indispensáveis inclusive a sua sustentação e atuação eficaz" (4, p. XI).

O poder se expande por toda a sociedade, assumindo as formas mais variadas, porém investido em instituições. O poder toma corpo através de técnicas de dominação. Esse poder, por ser mais concreto, atinge a corporalidade dos indivíduos. "Situa-se ao nível do próprio corpo social, e não acima dele, penetrando na vida cotidiana e por isso podendo ser caracterizado como micro-poder ou auto-poder" (4, p. XII).

O poder está no corpo e não na consciência. Aqui está a grande novidade em termos de dominação, introduzida por Foucault. Ele coloca o poder como soberano, e a ele ligado, encontramos um conjunto de procedimentos técnicos que realizam um controle minucioso do corpo, isto é, através dos gestos, das atitudes, dos comportamentos, dos discursos, dos hábitos.

O poder é difuso, é dado porque existe na sociedade como um todo. Ele está nos diferentes niveis da sociedade e não apenas reduzido ao Estado. Surge, portanto, o que Foucault denomina de micropoderes..

O social é, portanto, dividido, diluído em microcompartimentos que também devem ser observados. Desta forma, o econômico deixa de ser o único nível de análise social.

Foucault não rejeita o Estado. Ele procura mostrar outros tipos de poderes que existem na sociedade. Ele atribui ao poder do Estado uma especificidade.

"A análise ascendente que Foucault não só propõe, mas realiza, estuda o poder não como uma dominação global e centralizada que se pluraliza, se difunde e repercute nos outros setores da vida social de modo homogêneo, mas como tendo uma existência própria e formas específicas ao nível mais elementar. O Estado não é o ponto de partida necessário, o foco absoluto que estaria na origem de todo tipo de poder social e do qual também se deveria partir para explicar a constituição dos saberes nas sociedades capitalistas" (4, p. XIII-XIV).

O que se destaca na análise de Foucault é que "os poderes não se encontram localizados em nenhum .ponto específico da estrutura social, isto é, o poder funciona como uma rede de dispositivos ou mecanismos a que nada ou ninguém escapa, a que não existe exterior possível, limites ou fronteiras. Daí a importante e polêmica idéia de que o poder não é algo que se detém como uma coisa, como uma propriedade, que se possui ou não. Não existe de um lado os que têm o poder e de outro aqueles que se encontram dele alijados. Rigorosamente falando, o poder não existe; existem sim práticas ou relações de poder. O que significa dizer que o poder é algo que se exerce, que se efetua, que funciona e que se dissemina por toda a estrutura social" (4, p. XIV).

O poder é, portanto, partilhado como uma malha, como uma rede, sendo, conseqüentemente, uma relação.

Foucault rejeita uma concepção de poder inspirada pelo modelo econômico, que a considera como mercadoria" (4, p. XIV). Desta forma, distancia sua análise de poder da análise marxista.

"A idéia básica de Foucault é de mostrar que as relações de poder não se passam fundamentalmente nem ao nível do direito, nem da violência; nem são basicamente contratuais nem unicamente repressivas... É falso definir o poder como algo que diz não, que impõe limites, que 
castiga. A uma concepção negativa, que identifica o poder com o Estado e o considera essencialmente como aparelho repressivo, no sentido em que seu modo básico de intervenção sobre os cidadãos se daria em forma de violência, coerção, opressão, ele opõe, ou acrescenta, uma concepção positiva que pretende dissociar os termos dominação e repressão. $O$ que suas análises querem mostrar é que a dominação capitalista não conseguiria se manter se fosse exclusivamente baseada na repressão" (4, p. XV).

Assim pensando, Foucault procura analisar o poder sob um ponto de vista positivo e produtivo e não somente o seu lado negativo. O poder não tem a forma de uma imposição, mas tem a forma da produção. Ele não se impõe, mas se põe sutilmente, lentamente, ao passo que a forma jurídica de poder produz um efeito negativo, pois é instantâneo, rápido e eficaz.

Desta forma, Foucault destaca o que ele denomina de poder disciplinar. Este, apesar de humilde, é extremamente eficaz. O poder disciplinar é uma técnica, "um dispositivo, um mecanismo, um instrumento de poder, são métodos que permitem o controle minuncioso das operações do corpo, que asseguram a sujeição constante de suas forças e lhes impõe uma relação de docilidade - utilidade. É um diagrama de um poder que não atua do exterior, mas trabalha o corpo dos homens, manipula seus elementos, produz seu comportamento, enfim, fabrica o tipo do homem necessário ao funcionamento e manutenção da sociedade industrial capitalista" (4, p. XVII).

Esta colocação da questão do poder é importante sobretudo para as sociedades capitalistas, pois o corpo só vai se tornar força de trabalho quando trabalhado pelo sistema político de dominação que é peculiar ao poder disciplinar.

Foucault entende o poder disciplinar da seguinte forma: "em primeiro lugar, a disciplina é um tipo de organização do espaço. É uma técnica de distribuição dos indivíduos através da inserção dos corpos em um espaço individualizado, classificatório, combinatório. Isola em um espaço fechado, esquadrinhado, hierarquizado, capaz de desempenhar funções diferentes segundo o objetivo específico que dele se exige. Mas como as relações de poder disciplinar não necessitam necessariamente de espaço fechado para se realizar, é essa sua característica menos importante. Em segundo lugar, e mais fundamentalmente, a disciplina é um controle do tempo. Ela estabelece uma sujeição do corpo ao tempo, com o objetivo de produzir o máximo de rapidez, e o máximo de eficácia. Neste sentido não é basicamente o resultado de uma ação que Ihe interessa, mas seu desenvolvimento. E esse controle minucioso das operações do corpo ela o realiza através da elaboração temporal do ato, da correlação de um gesto específico com o corpo que o produz e, finalmente, através da articulação do corpo com o objeto a ser manipulado. Em terceiro lugar, a vigilância é um de seus principais instrumentos de controle. Não uma vigilância que reconhecidamente se exerce de modo fragmentar e descontínuo, mas que é ou precisa ser vista pelos indivíduos que a ela estão expostos como contínua, perpétua, permanente; que não tenha limites, penetre nos lugares mais recônditos, esteja presente em toda extensão do espaço... Finalmente, a disciplina implica um registro contínuo de conhecimento. Ao mesmo tempo que exerce um poder, produz um saber" (4, p. XVII-XVIII).

O poder disciplinar é humilde, porém eficaz, pois produz o indivíduo, tornando-o o seu mais importante efeito. O poder perde, como já foi dito, a forma judicial e assume a forma disciplinar, dando origem aos "corpos dóceis".

Também importante em relação ao poder é a sua relação mútua com o saber, pois, para Foucault não existe poder sem um saber e, em contrajartida, todo saber assegura o exercício do poder. 
A aplicação do poder disciplinar acaba sempre produzindo habilidades, sendo, portanto, um poder produtivo. Ele se impõe pela sugestão. As sanções são tênues, representadas por pequenas repreensões. Para Foucault, não existe o indivíduo retirado do seu meio social. Desta forma, a punição na forma de exclusão inexiste. O castigo é pela insinuação, pela intimidação.

Estes elementos constituem, portanto, o cerne do poder nas sociedades industriais.

Foucault não discute o poder de classe. Para ele o poder não se origina na classe, pois ele leva à disciplina, à ordem e conduz à sociedade de classes.

Desta forma, Foucault nos mostra o sistema de dominação na sua brutalidade. É a tecnologia do cotidiano, do detalhe que vai envolvendo o indivíduo suavemente, porém eficazmente. Ele é muito mais eficaz que o poder soberano. Não leva em consideração o indivíduo como indivíduo. Na nossa cotidianidade somos constantemente vigiados e punidos. A produção do que Foucault denomina de "corpos dóceis" é muito mais eficaz do que o controle das consciências, e esta afirmativa justifica em Foucault o abandono do conceito de ideologia como forma de poder.

GARCIA, L. B. R. - The ideology and the disciplinary power as domination forms. Trans/Form/Ação, São Paulo, 11: 53-59, 1988.

ABSTRACT: This article aims at a reflection on the Marxist concept of ldeology as an attemptto understand the transposition from the conscience level to the physical corporality level accomplished by Michel Foucault, as a form of instituting disciplinary power over the individual and also as a means of domination which is more effective than conscience itself.

KEY-WORDS: Ideology; alienation; dialectic; conscience; false conscience; power, micro power, disciplinary power.

\section{REFERÊNCIAS BIBLIOGRÁFICAS}

1. CHAUl; M. - O que é ideologia. São Paulo, Abril Cultural, Brasiliense, 1984.

2. FOUCAULT, M. - Microffsica do poder. Rio de Janeiro, Editora Graal, 1982.

3. GALLIANO, A.G. - Introdução à sociologia. São Paulo, Harper \& Row do Brasil, 1981.

4. MACHADO, R. - Por uma genealogia do poder. In: FOUCAULT, M. - Microffsica do poder. Rio de Janeiro, Graal, 1982.

5. MARX, K. \& ENGELS, F. - A ideologia alemã. Lisboa, Editorial Presença, 1976.

\section{BIBLIOGRAFIA CONSULTADA}

DURKHEIM, E. - As regras do método sociológico. São Paulo, Ed. Nacional, 1963.

FOUCAULT, M. - Vigiar e punir. Petrópolis, Vozes, 1984.

Trans/Form/Ação, São Paulo, 11: 53-59, 1988. 